cause is removed. On the other hand, malignant disease may pervade the whole system, and become developed in the mamma or any other organ, and exist in the form of a tumour for months together, the health evidently giving way, while the absorbent glands remain unaffected. The conclusion is, that it is not always adrantageous or safe to amputate when the absorbent glands are sound; nor, when they are swollen and tender and infamed, do they present any absolute proof that the whole system is contaminated. In those cases where the question of excision can be entertained at all, it is impossible to tell whether this secondary affection of the absorbent system be merely the effect of irritation, or an actual extension or translation of malignant diseases. How, then, can any thinking man regard it as an important indication for or against an operation?

Happily, hospital surgeons are becoming at length practically alive to the fallacy of this distinction; and it is one of the most pleasing features of the improved condition of modern surgery, that the treatment of morbid growths by extirpation, is now the exception, and not, as formerly, the rule.

The medical treatment of morbid growths, and the efficacy of alteratives in arresting their advance or destroying them altogether in cases unfitted for operation, will form the subject of a future paper.

Dec. $12,1848$.

\section{CLINICAL ILLUSTRATIONS.}

\section{CANCER AND FIBROUS TUMOUR OF THE} UTERUS : CASE AND REMARKS.

By Edward Ballard, M.D., Leamington,

Late Senior Physician to the St. Pancras Royal General Dispensary, and Medica! Tator in Unirersity College, London.

Having been induced to offer as the first of $\mathrm{my}$ clinical illustrations a case of an unusual form of uterine disease, it may be as well for the present to confine my observations to such affections of the womb and its appendages as hare come under my. notice and treatment in the course of my Dispensary practice; in doing so it shall be my endeavour to select from among the unpublished cases which I have collected, those which on the one hand I have had the opportunity of recording with the greatest exactitude, or or the other which appear to illustrate important facts in pathology or practice. Nor shall I consider any apology needed on account of the details which $I$ may think it desirable to enter into, believing as $I$ do that there is no fact which well observed may not be without its value, and that if from circumstances it is not appreciated fully by myself, it may be of such a nature as to fill up some important hiatus in the reasonings of others.

\section{Case.}

Injury to the Trunk; Menorrhagia; Aldominal Tumour; Vaginal Discharges; Involuntary flow of Urine; Death.-Post-mortem examination :Filrous Tumour; Scirrhus; Encephaloid and Fungus Homatodes of Uterus; Ovarian Tumour, \&c.

This case was seen during life by my friend and colleague Dr. A. P. Stewart, who, after death gave me the opportunity of making an examination of the body. The following history I draw up from information derived from the patient's sister and a woman in whose house she resided, and it was kindly corrected by Dr. Stewart from what he recollected of the symptoms.

M. A. L., aged 42, a native of Norfol $k$, but having resided ever since she was twenty years of age in London, where she has lived upon the town during all that period as a conmon prostitute. The court in which she lived was one of the clcsest and most unhealthy in St. Pancras parish, and inhabited almost entirely by the class of persons to which she herself belonged. She was the eldest of eleven, and lost two brothers of consumption, one at the age of 19 , the other at that of 23 years. She became a patient at the St. Pancras Dispensary, under the care of Dr. Stewart, very shortly before ber death.

Although an inveterate spirit drinker, she had always had sufficient wholesome nourishment, and up to nine years ago is said to have enjoyed a good state of healtb. She had one child shortly after she came to London. About nine years ago a cab knocked her down in the New Road, and the wheel passed over her body. She seems to have considered herself at this time in the family way, but upon this there prevails some uncertainty. From this injury she used to date all her ailments, although it appears probable that previously she bad been subject to occasional flatulent pains and thelling of the belly, which eructation always relieved. However, from the lime of being run over, she was subject to menorrhagia, often of a month or six weeks duration, blood coming from her in clots. For the last four or five years and more, especially for the last three, she had noticed the abdomen to be enlarging to a degree quite unusual to her, and this, too, principally at the lower part; and she complained from time to ine of the food she took disagreeing with her; and two years ago she began, for the first time, to complain of twisting pains, "as if her intestines were being tied into knots." In the month of February last year, (this report was drawn up in September, 1846,) she began to complain in addition of darting pains at the bottom of the belly, and swelling of the legs, which induced her to place herself in the Middlesex Hospital, where she was told that there was "a tumour in thé abdomen." Being of a very reserved and uncommu"nicative disposition, it is highly probable that the pains she suffered had lasted for a long time before she made any complaint of them to her neighbours, and then did so only when their severity extorted it. She never suffered from any remarkable vaginal discharge till twelve or eighteen months before her death. About a 
week before last Christmas she became unable to hold her urine for the ordinary period, and only passed it in small quantities at a time. She also told her sister that "a substance had come from her like bone and fesh," but she was frightened very much at it, and had thrown it away without further examination, and at the same time she suffered pain around the umbilicus and at the bottom of her back. Four months ago the raginal discharge becaine very aburdant and offensive, and ber strength was reduced, but not extremely so. From six to nine weeks before her death, a black substance was discharged by the vagina three or four inches in diameter, which, according to the testimony of some one who saw it, resembled very much the matter found in the uterus after death, since then she appeared to have lost all control over her bladder, the urine passing from it constantly and involuntarily. At Christmas, too, ber complexion began to assume the cancerous tint, and she began to lose her flesh. About a month or three weeks before her death there appeared some cedena of the ankles, which slowly extended to the thigh. She did not take to her bed, however, till three days before she died, during which time she lost her appetite, and passed ber stools involuntarily. For the last nine days the odour of the discharges from the vagina was exceedingly offensive. She used to complain to Dr. Stewart very much of pain in the scapulæ. She never was sick or vomited, and her bowels were regular throughout. During the last three days that she was in bed she drank excessively of spirits and laudanum. She died on September 5th, 1846.

Examination of the Body fifly-nine hours after Death.-General, but not extreme, emaciation. Below the umbilicus their appeared a somewhat conical projection, occasioned by a tumour in the abdomen, which became much more obvious on handling it, and was manifestly of irregular outline; it was felt to extend upwards as high as the umbilicus, and laterally: to within three fingers' breadth of the iliac spines, being most prominent in the middle line, and receding towards the sides, approaching the right, nearer than the left, ilium. The irregularity of outline was most remarkable on the right side and upper part, where it felt tuberous. It was moveable to a small extent; percussion over it elicited a dull note, becoming, howerer, rather less so towards the sides. Resonance pretty natural over the upper half of the abdomen. On laying open the abdomen by a vertical incision, the tumour was displayed, occupying the space between the pubes and the umbilicus, and descending into the pelvis, having on its right side the enlarged and diseased ovary, and being covered by the omentum which was adherent to the surface of the latter. The tumour did not adhere at all to the abdominal parietes. It consisted of the enlarged and diseased uterus, to which the left Fallopian tube was adherent along its left border, as also was the left orary. The uterus, when removed, measured ten inches in length, and six inches in width, at the widest part. Its surface was eren and smooth anteriorly, but presented tuberiform elevations at, the fundus, and posteriorly; two, hard and bony, imbedded in the tissue, projected at the top. They were about three inches in diameter, and there were smaller tumours posteriorly, of about the size of a marble or walnut. The cervix uteri had completely disappeared, and the os was dilated to the extent of about two inches in diameter, its margin being thin, flabby, and congested, and it displayed within the uterus a dark-brown mass. On laying open the cavity of the uterus by a rertical incision on its anterior surface, it was found to contain a mass of fungus hæmatodes, which was not adherent anteriorly to the wall of the organ, but posteriorly and laterally was connected with irregular projections, of various sizes into the cavity, of cerebriform cancer. The mass of fungus hæmatodes was of a very dark reddishbrown colour, breaking down under the finger, but still presenting an amount of cohesion, which was greatest as it approximated to the cerebriform masses. In parts itbroke down on pressure, into a dirty grumous liquid. It appeared to be in masses, which were connected to one another by films and thin cellular bands, pretty easily broken down, and these masses, when cut into, were seen to be rather granular on the section. The cancerous masses projecting into the cavity, when cut into, were found to be soft, traversed by numerous bands, and to present much the appearance of the surface of an infant's brain. In no part did this matter reach the outer surface of the organ. Some few flaky little pieces of bone were picked out of the hæmorrhagic mass near its attached portion. The tumours which projected externally were of two kinds; some of the smaller exhibited, on section, the aspect of scirrhous cancer, and exuded a cancerous juice on being scraped; others presented a structure similar to that of the two large tumours of the fundus. The latter were united by what appeared to be scirrhous texture. The largest was about the size of a duck's egg, oral in form, and consisted of a mass of fleshylooking matter, fasiculated like muscular tissue, and pale, as if rendered so by a short maceration in water. This matter was enclosed in a flexible fibrous cyst, containing patches of calcareous matter. At one end of it was a small entirely calcareous cyst, of about a line, or sometimes more, in thickness, enclosing a similarly fibrous matter, but dense, and less like muscle, of a pale yellowish tinge, and drier than the former; it was evidently of longer standing than the greater part of the tumour. The other tumour which lay beside it was of a rounded form, and appeared to consist of several, aggregated and united, the walls of all being very dense and calcareous, and the enclosed fibrous or fleshy-looking matter varying from a pale red 'to a yellowish colour, and being denser, and of a drier texture than that before described. A smaller tumour appeared in a transition state; its cyst was partly osseous and partly flexible, the enclosed matter being denser and yellower near the former, and redder and more flesh-like near the latter, portion. None of these tumours reached the peritoneal surface of the womb, and although causing considerable projection, they were covered by a layer of hypertophied uterine tissue. The general tissue of the uterus was hypertrophied, even where not diseased; the thickness of the anterior wall near the fundus was nearly an inch, and it thinned off gradually towards the dilated os. 
The right ovary was converted into severul masses similar to the fibrous tumour of the uterus, each more or less completely enclosed in an osseous cyst, the side of each tumour most ossified being denser also, and yellowish in colour. The kidneys were rather smaller than natural, very flabby and watery, very pale, and the cortical portion much diminished in width. There was nothing deserving record amiss with the other abdominal or thoracic organs. The cancerous tissue was subınitted to microscopic examination. The brown hæmorrhagic matter in the cavities presented long and short caudate and spindleshaped cells, as well as others which were round, compound, and nucleated-granules and blood-cor-t puscles in various conditions. The blood corpuscles and caudate spindle-shaped cells were not seên in the encephaloid matter. They were seen, however, in the fluid scraped from the scirrhus, along with crystalline matters and fibres.

\section{REMarKS.}

Pathology.-1. The limitation of the disease to the womb, although it there produced the most tremendous ravages, is a fact generally observed in cancer of this organ. If we may rely on the small number examined by $M$. Ferrus, a little more than a fifth alone bave presented, in addition, a secondary cancerous complication. My own experience leads me to coincide in this respect with the general statement. I have, however, in one case met with uterine cancer occurring secondarily to cancer of the mamma, a thing so unusual that their union in the same person is generally denied. 2. The part of the organ affected was remarkable. The cervix, as every one's experience can testify, is the most common seat of cancer of the womb ; at any rate, if the body be diseased, it becomes so by the spreading of the adventitious growth from the former part. Here, however, the cervix was free, and the body was the only part which suffered, The posterior wall, too, was alone affected. Persons accustomed to dissect cancerous wombs are aware of this disposition of the posterior part of the body to take precedence of the anterior in presenting the morbid change, and the same tendency is noticed in the posterior lip, where the cervix is the part attached. The outer lajer of the uterine tissue again was free from cancerous deposit, as if the disease had commenced on the inner surface, perhaps, in the submucons tissue, or in that part of the wall which was nearest to it. The freedom of the anterior wall was the more remarkable, that there was no trace of disease on its inner sur. face to indicate that it had lain so long in contact with the fungous mass which projected from the posterior. 3. The unusucul combination of scirrhus with encephaloid, the latter the more unusual of the two varieties which affect the womb, the occurrence of colloid in it at any time being exceedingly doubtful. The fungoid and hæmorrhagic growth of it from the interior of the bcdy, so as to form a soft tumour, distending its cavity, is very uncommon; it was the "fungus hæmatodes" of Hey and others, and nothing more than an accidental condition of the encephaloid matter. 4. The co-existence of the fibrous tumours with cancer of the uterus deserves a few observations. It is common to find them together, and it would be a matter of much interest to determine in what relation they stand to one another. In the present instance everything connected with their anatomical peculiarities, and with the history of the patient's ailments, would lead to the belief that they had preceded the development of the cancer; they presented distinctly two periods of formation, the more recent, perhaps, was simultaneous with that of the cancer. It happens about as oiten that the fibrous growth succeeds the cancerous, and this not of the uterus or ovaries alone; but judging by my own expericnce, of the pylorus, or other abdominal or more distant organs, I have found it occur more rarely as a solitary affection, than in conjunction with cancer or other tumours in important organs of the body. I would not, however, be understood as believing that the fibrous tumour has any generic similarity to the cancerous, or that it exhibits any special disposition to assume a cancerous character, as an after-phase of its development; on the contrary, it has its own modes of morbid progress, one of which is illustrated in the case under consideration. Still the coincidence of the two kinds of growth is highly interesting, especially when we keep in mind that the only element necessary to convert a fibrous, into a scirrhous, tumour, is the interstitial deposition of cancercells. I make no allusion to the arrangement of the fibrous element, which, on competent authority, is essentially different in the two cases, but merely to the presence of certain microscopic elements; because, as I remarked before, fibrous tumour and cancer must by no means be confounded. 5. Hypertrophy of the uterine tissues when free from morbid growths, was a remarkable feature in the condition of the organ, and had occurred to an extent beyond anything I had formerly witnessed in cancer of the womb. Dr. Walsbe, in speaking of this complication, says he has known the uninfiltrated portion of the uterus acquire three times its natural dimensions. It is in the soft, rather than in the scirrhous, cancer of the womb, that this bypertrophy prevails. 6. The condition of the cervix and os uteri deserves remark; the latter was absolutely lost by atrophy and distension, while the os was singularly dilated. I have notes of another case of somewhat similar alteration of the cerrix, where the womb was the seat of an enormous fibrous tumour. At a future period I shall probably relate it. In both instances the cause was probably the same 2s that which determines similar changes in advanced pregnancy. 7. Although I purposely omitted it from. the repart as of accidental origin, I would here desire. to allude to a phenomenon presented by the uterus 
when removed from the pelvis,-namely, that as it lay upon the table, percussion over the central part of the lody elicited a distinct resonance. There was no mistake about this, as the experiment was repeated, and Dr. Stewart heard it as well as myself. I mention it here partly because it gives me an opportunity of alluding to a similar resonance which I have observed over the right front of the chest in a man who had died with pneumonia of the right lung. In this case the resonance was noted as "almost tympanitic." This, too, was confirmed by the testimony of a medical friend who assisted me in the examination, and was surprised at seeing a consolidated lung enclosed in a resonant chest. Both these occurrences must be attributed, not to any peculiar condition of the uterus or chest, but to some peculiarity in the mode or direction of the stroke, which the solid tissue conducted to the vibrating table on which they severally rested.

Physical Signs. - A few observations, may not be out of place in relation to the physical evidence of the uterine disease as presented by external examination after death. In the first place there was not merely fulness, but a positire projection, obvious to the eye, at the lower part of the abdomen, which immediately attracted the attention on uncovering the latter. This was due to the tuberiform elevations resulting from the fibrous tumours in the substance of the womb. I cannot tell whether this sign existed during life, but at all events the tumours of the uterus must have been palpable to the hand. The fact that such can be felt, teaches this lesson, that we are not immediately to conclude on this account that they are subperitoneal. The determination of this point is of practical importance, since uterine hæmorrluage is far more rarely. connected with them in this situation than when placed near the inner surface; still should the error occur, it would be on the right side, as it would lead to the further investigation. The general enlargement of the womb felt by the hand could only have been mistaken for that arising from pregnancy. A vaginal examination, howerer, during life, had the enlargement been detected at that time, would readily have distinguished between this and hypertrophy of the walls. In the former the cervix would not have been so completely obliterated at the period supposed to be arrived at, and the enlargement of the organ would have been felt more towards its anterior than towards its posterior walls. The partial mobility of the enlarged organs was indicative of what was observed after death,-namely, the absence of inportant adhesions, or of the extension of cancerous degeneration into the broad ligaments and neighbouring organs. In all this, however, there was no evidence of cancer of the womb. What, however, would have been ascertained, had raginal examination been practised during life ? A stretched, thinned, and, so far as its natural form was concerned, an obliterated cervix; the os uteri most unusually opened and extended in its diameter, and occupied by a fungous growth, which would easily have been recognized as extending, at any rate, some way into the general carity. This state of things only occurs, so far as I am aware, when the uterus has been distended by growth or deposit into its carity, or by very unusual degeneration and tumour in its walls. The two cases might have been distinguished by ascertuining the size, duration, and contents of the uterine carity, by means of the finger, specula:am, o: uterine sound. In the present instance I think there should have been no mistake in the diagnosis, had all the available means been adopted for ascertaining the physical condition of the diseased organ.

Symptoms. - In every chronic affection the symptoms of the disease are divisible into certain periods, which the practitioner should ever keep in mind. Before a chronic local disease can be said to have plainly manifested itself, there is mostly discernible a period of greater or less duration in which the patient is "ailing;" the general health is defective, and there is some degree of general debility and slightly disordered function, mostly exhibiting itself in the digestive and circulating system, and in the condition of the urine; these, from their very gradual accession, are commonty overlooked or attributed to occasional or incidental coincidence. It may be well if the acuteness of the physician prevents his being so readily led astray, and if he be impressed with the fact that so intimately is every function of the body connected with every otler, that a disturbance in one, however trifling in amount, yet if prolonged in duration, ensures most certaibly a derangement of the rest; it may be well, moreover, for the patient if the original source of his disorder be timely discovered, and be such as medical art can reach. The next stage is that of formation of the local disease. This may date its commencement from some accidental occurrence, some trifing local injury, or the latter may, by drawing attention to the seat of disease, merely unveil what had perhaps for months or years been slowly, insidiously, and painlessly, yet irremediably, not only disturbing function, but undermining structure. The symptoms of this period pass gradually, or perhaps after a prolonged latency, with the most fatal and uncontrollable rapidity, into those of the confirmed disease, in which for the most part the sensations of the patient direct the practitioner pretty surely to its seat, and in which far more frequently than at an earlier period of its derelopment the assistance of his art is commonly sought. The last stage is that which immediately precedes dissolution; the symptoms of the local affection may be obvious and urgent, but they are very often marked by those which arise from excessive constitutional prostration, or from accidents - the result of the original disease, or 
of the depression of the powers of life. The true physician's art is in this, and perhaps even in the preceding period, limited to the melancholy, but not the less important duty of sooihing by his presence, his attention, and by the moral influence which he cannot fail to exercise, the mental disquietude of his patient, and, by gentle remedies and incessant watchfulness, of alleviàting his bodily suffering, and rendering less troubled his journey to the grave.

In the present instance there is little record of the 8tate of the patient's health previous to the development of the uterine disease, the only notice of ailment being, that she had probably suffered from the same abdominal flatulence and pain which used to troutré her more or less through the whole period of her illness. The first symptom of uterine disease was the occurrence of menorrhagia. Violent and repeated flooding, not to be accounted for by something in the state of the general or portal circulation, should always lead the practitioner to enquire into the structures condition of the uterus, and to institute a most careful investigation into the physical state of the organ. It to nost likely that its first occurrence was determined not by the cancerous disease, for this was of more recent origin, but by the fibrous tumours in the uterine walls; and it is much more frequently when thesa spproach the inner, nearer than the outer, surface of the organ, that they occasion hæmorrhage. I am not: disposed to place any reliance on a "clotted" discharge as indicating uterine disease. Darting pain at the lower part of the belly, swelling of the legs, and vaginal discharge, would appear to have ushered in the more serious cancerous affection. The pain, however, was not of the all-absorbing churacter which is observable in the more ordinary forms of uterine cancer, being perhaps complained of less than any thing that the patient suffered, not even being such as to compel her to keep her bed; nor was it as in cancer originating in the eervix, described as darting through the pelvis. The character of the vaginal discharge when it first appeared could not be ascertaiped; but nine months before her death there passed from the ragina a substance described as similar to bone and lesh.' A better similitude could not have been selected to represent the character of the fibrous tumours existing in the uterine wall, one of which had no doubt become enucleated in the progress of the disorganization. I would again impress on all who are called on to treat diseases of the wowb, the importance of relying in no case on the statements of the patient herself as to the nature of the matters which pass from the vagina. They are as important as means of diagnosis, as the discharge from any mucous surface in the body, as much so as those of the lungs in pneumonia, or of the bowels in abdominal disease. The examination of this mass would of itself bave afforded the most conclusive evidence, not only of fibrous tumours existing in the uterine wall, but also of their situation with respect to the interior of the organ, while the calcareous degeneration it bad undergone would have pointed it out as of no recent formation, and as the probable cause of the protracted menorrhagia. It was not until some months after this period that the raginal discharge became offensive. It is not unlikely that the separation of the tumour gave-room for the exuberant fungous growth which sprouted from the encephaloid mass into the cavity of the organ, just as in superficial cancer the removal of a restraint upon its surface is followed by a similar result. But I have not yet done with the instruction derivable from careful examination of vaginal discharges. We are informed that a few weeks before death a black substance passed from the ragina resembling the fungoid growth which filled the cavity of the womb-no doubt part of it. Had a portion been placed under the microscope, little doubt of its cancerous nature would have existed in the mind of the examiner. It is to be regretted that among practitioners in general this means of investigation is so little resorted to in the diagnosis of uterine disease. Applied to the urine, it has opened a field of the most valuable information, and advanced in an extruordinary degree our knowledge of renal disorders.

The discharge of this fungoid matter ushered in the latter symptoms of the complaint, which had reference, not to the uterus alone, but to adjoining organs. $A$ difficulty in retaining her urine, which had annoyed the patient ever since the discharge of the fibrous mass, passed on into complete incontinence, partly due to paralysis, and partly the result of diminished capacity of the bladder from the bulk of the enlarged womb. She lost her appetite, and with it the remaining portion of her strength, and the spbincters of the anus ceased to perform their function. These are common occurrences during the last days of uterine disease.

\section{Tospital Reports.}

QUEEN'S HOSPITAL, BIRMINGHAM.

CLINICAL REPORTS OF SURGICAL CASES UNDER THE TREATMENT OF PROFESSOR' SANDS COX, F.R.S., SENIOR SURGEON TO' THE HOSPITAL.

Reported by Mr. Peter Hinckes Bird, late Resident. Medical Officer.

Case XVI.

FRACTURE OF BOTH GONES OF THE LEG.

John Jelf, aged 21, was admitted into the Queen's Hospital April 13th, 1847, under the care of Professor Cox. He is a labourer; temperate and healthy. Ho states that about a quarter of an hour previous to his adưfission into the Hospital, whilst lifting a heavy 